\title{
Postprandial incretin and islet hormone responses and dipeptidyl-peptidase 4 enzymatic activity in patients with maturity onset diabetes of the young
}

\author{
Signe Harring Østoft ${ }^{1,2,3}$, Jonatan Ising Bagger ${ }^{1,2,3}$, Torben Hansen ${ }^{3,4}$, \\ Bolette Hartmann $^{2,3}$, Oluf Pedersen ${ }^{3}$, Jens Juul Holst ${ }^{2,3}$, Filip Krag Knop 1,2,3 \\ and Tina VilsbølI ${ }^{1}$
}

${ }^{1}$ Center for Diabetes Research, Gentofte Hospital, University of Copenhagen, Kildegårdsvej 28, DK-2900 Hellerup, Denmark, ${ }^{2}$ Department of Biomedical Sciences, Faculty of Health Sciences, University of Copenhagen, Copenhagen, Denmark, ${ }^{3}$ NNF Center for Basic Metabolic Research, University of Copenhagen, Copenhagen, Denmark and ${ }^{4}$ Faculty of Health Sciences, University of Southern Denmark, Odense, Denmark
Correspondence should be addressed to S H Østoft

Email

s.ostoft@dadlnet.dk

\begin{abstract}
Objective: The role of the incretin hormones in the pathophysiology of maturity onset diabetes of the young (MODY) is unclear.

Design: We studied the postprandial plasma responses of glucagon, incretin hormones (glucagon-like peptide 1 (GLP1) and glucose-dependent insulinotropic polypeptide (GIP)) and dipeptidyl-peptidase 4 (DPP4) enzymatic activity in patients with glucokinase (GCK) diabetes (MODY2) and hepatocyte nuclear factor $1 \alpha$ (HNF1A) diabetes (MODY3) as well as in matched healthy individuals (CTRLs).

Subjects and methods: Ten patients with MODY2 (mean age \pm s.E.M. $43 \pm 5$ years; BMI $24 \pm 2 \mathrm{~kg} / \mathrm{m}^{2}$; fasting plasma glucose (FPG) $7.1 \pm 0.3 \mathrm{mmol} / \mathrm{l}: \mathrm{HbA} 1 \mathrm{c} 6.6 \pm 0.2 \%$ ), ten patients with MODY3 (age $31 \pm 3$ years; BMI $24 \pm 1 \mathrm{~kg} / \mathrm{m}^{2} ; \mathrm{FPG} 8.9 \pm 0.8 \mathrm{mmol} / / ;$ $\mathrm{HbA} 1 \mathrm{c} 7.0 \pm 0.3 \%$ ) and ten CTRLs (age $40 \pm 5$ years; BMI $24 \pm 1 \mathrm{~kg} / \mathrm{m}^{2}$; FPG $5.1 \pm 0.1 \mathrm{mmol} / \mathrm{l} ; \mathrm{HbA} 1 \mathrm{c} 5.3 \pm 0.1 \%$ ) were examined with a liquid test meal.

Results: All of the groups exhibited similar baseline values of glucagon (MODY2: $7 \pm 1 \mathrm{pmol} / /$; MODY3: $6 \pm 1 \mathrm{pmol} / /$; CTRLs: $8 \pm$ $2 \mathrm{pmol} / \mathrm{l}, P=0.787$ ), but patients with MODY3 exhibited postprandial hyperglucagonaemia (area under the curve (AUC) $838 \pm 108 \mathrm{~min} \times \mathrm{pmol} / \mathrm{l})$ as compared to CTRLs $(182 \pm 176 \mathrm{~min} \times \mathrm{pmol} / \mathrm{l}, P=0.005)$ and tended to have a greater response than did patients with MODY2 ( $410 \pm 154 \mathrm{~min} \times \mathrm{pmol} / \mathrm{l}, P=0.063)$. Similar peak concentrations and AUCs for plasma GIP and plasma GLP1 were observed across the groups. Increased fasting DPP4 activity was seen in patients with MODY3 (17.7 \pm $1.2 \mathrm{mU} / \mathrm{ml})$ vs CTRLs $(13.6 \pm 0.8 \mathrm{mU} / \mathrm{ml}, P=0.011)$, but the amount of activity was similar to that in patients with MODY2 $(15.0 \pm 0.7 \mathrm{mU} / \mathrm{ml}, P=0.133)$.

Conclusion: The pathophysiology of MODY3 includes exaggerated postprandial glucagon responses and increased fasting DPP4 enzymatic activity but normal postprandial incretin responses both in patients with MODY2 and in patients with MODY3.
\end{abstract}

\section{Introduction}

Maturity onset diabetes of the young (MODY) designates monogenic forms of diabetes characterised by i) early onset of diabetes (often before the age of 25 years), ii) a positive family history of diabetes, iii) hyperglycaemia without a history of ketoacidosis, iv) measurable circulating C-peptide levels lasting longer than 3 years after (c) 2015 European Society of Endocrinology Printed in Great Britain
Published by Bioscientifica Ltd. 
diagnosis, and v) the absence of islet cell antibodies and glutamic acid decarboxylase (GAD) autoantibodies at the time of diagnosis $(1,2)$. MODY is inherited in an autosomal and dominant fashion, with the most common forms being glucokinase (GCK) diabetes (MODY2; caused by mutations in the GCK gene) and hepatocyte nuclear factor $1 \alpha$ (HNF1A) diabetes (MODY3; caused by mutations the transcription factor $H N F 1 A$ gene) $(1,3,4)$, and it causes $\sim 1-2 \%$ of all cases of diabetes (5). MODY3, which is the more prevalent of the two forms $(1,3,4)$, is characterised by a rapid progression of glucose intolerance. The diagnosis is often made after the sudden occurrence of symptoms such as polyuria and polydipsia, and many patients are therefore misclassified as having type 1 diabetes $(6,7)$. A defective GCK activity in patients with MODY2 results in impaired $\beta$ cell glucose sensing and, consequently, an increased glucose threshold for insulin secretion, but the patients seem to maintain a preserved insulin secretory capacity (8).

Glucagon serves to maintain plasma glucose (PG) concentrations within the normal range during fasting and counteracts the glucose-lowering effect of insulin. The pathogenesis of type 2 diabetes involves both fasting and postprandial hyperglucagonaemia contributing importantly to the hyperglycaemia of these patients $(9,10)$.

The incretin hormones glucose-dependent insulinotropic polypeptide (GIP) and glucagon-like peptide 1 (GLP1) are secreted from endocrine mucosal $\mathrm{K}$ and $\mathrm{L}$ cells respectively in the small intestine in response to presence of nutrients in the gut lumen (11), and they interact with the GIP and GLP1 receptors respectively. Their insulinotropic effect is strictly glucose-dependent and kicks in at the beginning of a meal (12). GLP1 also inhibits glucagon secretion from pancreatic $\alpha$ cells and thereby reduces hepatic glucose production, which further contributes to the blood glucose-lowering effect of GLP1 (13). Biologically active GIP and GLP1 (i.e. the intact forms of the hormones) are rapidly and extensively metabolised by the enzyme dipeptidyl-peptidase 4 (DPP4), which cleaves the N-terminal dipeptide from the hormones and thereby inactivates them (11). Interestingly, the transcription factor HNF1A has been shown to be necessary for promoter activation of the DPP4 gene (14). Thus, patients with MODY3 may have altered DPP4 expression (and overall DPP4 enzymatic activity) and therefore potentially also altered levels of intact GLP1 and GIP after meal ingestion.

Very little is known about postprandial plasma glucagon profiles in patients with MODY. Our group previously found hyperglucagonaemia following an oral glucose tolerance test (OGTT) in patients with MODY3 and normal responses in patients with MODY2 (15).
Furthermore, the postprandial release of the incretin hormones has only been studied sparsely in patients with MODY3 $(15,16)$ and has only been studied in patients with MODY2 after an OGTT $(15,17)$. Studies in patients with type 2 diabetes have shown reduced responses of the incretin hormones to a mixed meal $(18,19)$. Thus, the postprandial responses of the incretin hormones and glucagon in patients with MODY remain unclear. The aims of the present study were to examine fasting and postprandial circulating levels of glucagon, GIP, GLP1 and insulin in the two most common forms of MODY, MODY2 and MODY3, and in matched healthy individuals (CTRLs). In addition, DPP4 activity in plasma as well as its consequences for the plasma levels of intact and metabolised incretin hormones was determined.

\section{Subjects and methods}

The protocol was approved by the Scientific Ethical Committee of the Capitol Region (registration number H-1-2010-130) and was registered at ClinicalTrials.gov (ID: NCT01342939). The trial was conducted according to the principles of the Helsinki Declaration II.

\section{Subjects}

Anthropometric data are listed in Table 1. All MODY patients had established heterozygous loss-of-function mutations in the HNF1A gene (HNF1A diabetes, or MODY3) or in the GCK gene (GCK diabetes, or MODY2). All of the mutations were confirmed by sequencing, and patients were recruited from Steno Diabetes Center, Gentofte, Denmark. Mutations were considered pathogenic if they met at least one of the following criteria: i) previously published reports on the disease causing the effect of the specific mutation; ii) the presence of a truncating mutation; and/or iii) the co-segregation of the mutation with a MODY phenotype within the family and the absence of the variant in normal chromosomes. Ten patients with MODY2, ten patients with MODY3 and ten CTRLs were included in the study. Three MODY2 patients were related, including two siblings and their mother (GCK-6, GCK-7 and GCK-8). The specific mutations are listed in Table 2. Nine of the patients with MODY2, all of the patients with MODY3 and nine of the CTRLs had been included in a previously published study wherein we investigated the incretin effect on and hormone responses to oral and intravenous glucose (15).

Inclusion criteria included: Caucasians with MODY3 or MODY2 above 18 years of age, BMI of $>19 \mathrm{~kg} / \mathrm{m}^{2}$, 
Table 1 Anthropometric data.

\begin{tabular}{|c|c|c|}
\hline & CTRL (1) & MODY2 (2) \\
\hline$n$ (females) & $10(6)$ & $10(8)$ \\
\hline Age (years) & $40 \pm 5$ & $43 \pm 5$ \\
\hline BMI $\left(\mathrm{kg} / \mathrm{m}^{2}\right)$ & $24 \pm 1$ & $24 \pm 2$ \\
\hline FPG (mmol/l) & $5.1 \pm 0.1 *(2,3)$ & $7.1 \pm 0.3^{*(1)}$ \\
\hline $\mathrm{HbA1c}(\%)$ & $5.3 \pm 0.1 *(3)$ & $6.6 \pm 0.2^{*(3)}$ \\
\hline $\mathrm{HbA1c}(\mathrm{mmol} / \mathrm{mol})$ & $34 \pm 1 *(3)$ & $49 \pm 2 *^{(3)}$ \\
\hline HOMA-IR & $1.8 \pm 0.1$ & $3.6 \pm 1.0$ \\
\hline
\end{tabular}

\begin{tabular}{c}
\hline MODY3 (3) \\
\hline $10(5)$ \\
$31 \pm 3$ \\
$24 \pm 1$ \\
$8.9 \pm 0.8^{*(1)}$ \\
$7.0 \pm 0.3^{*(1,2)}$ \\
$53 \pm 3^{*(1,2)}$ \\
$1.9 \pm 0.2$ \\
\hline
\end{tabular}

\begin{tabular}{c}
\hline $\boldsymbol{P}_{\text {ANOVA }}$ \\
\hline $0.366^{\mathrm{a}}$ \\
0.137 \\
0.945 \\
$<0.001$ \\
$<0.001$ \\
$<0.001$ \\
0.107 \\
\hline
\end{tabular}

Data are means \pm s.E.M. $P$ values are derived from one-way ANOVA for inter-load variations. Asterisk indicates significant differences $(P<0.05)$ from the group given in parentheses in the inter-load variations (post hoc analysis). ${ }^{2} \chi^{2}$ test for sex difference.

normal haemoglobin (males $>8.2 \mathrm{mmol} / \mathrm{l}$; females $>7.2 \mathrm{mmol} / \mathrm{l})$, normal blood pressure $(<160 / 100 \mathrm{mmHg}$ ), informed consent, negative pregnancy test (women) and the absence of islet autoantibodies and GAD65 autoantibodies. Exclusion criteria included: heart failure (New York Heart Association class III-IV), plasma creatinine levels of $>130 \mu \mathrm{mol} / \mathrm{l}$ and/or albuminuria, liver disease (alanine aminotransferase and/or aspartate aminotransferase $>2 \times$ the upper normal serum levels), anaemia, pregnancy or breast-feeding, the inability to complete the trial and treatment with medicine that could not be paused for $12 \mathrm{~h}$.

Six out of the ten patients with MODY3 were treated with oral blood glucose-lowering drugs (glimepiride, repaglinide, tolbutamide and/or metformin). The remaining MODY patients $(n=14)$ were treated with diet only. None of the patients had impaired renal function or impaired liver function or suffered from cardiovascular disease, autonomic neuropathy or retinopathy. None of the CTRLs had a family history of diabetes, and according to a $75 \mathrm{~g}$ OGTT performed immediately before inclusion in the study, they all had normal glucose tolerance. Apart from the oral glucose-lowering drugs, none of the participants were treated with drugs that are suspected to influence PG, insulin, C-peptide, glucagon or incretin hormone responses. All of the participants agreed to participate after receiving oral and written information.

\section{Experimental protocol}

Following an initial screening visit, each participant was examined with a liquid test meal $(350 \mathrm{ml}$ Nutridrink Compact (Nutricia A/S, Allerød, Denmark) containing $525 \mathrm{kcal}: 65 \mathrm{~g}$ carbohydrate, $20 \mathrm{~g}$ fat, $21 \mathrm{~g}$ protein). One and a half grams of paracetamol (Panodil, GlaxoSmithKline $\mathrm{A} / \mathrm{S}$ ) dissolved in $50 \mathrm{ml}$ water was added to the test meal for the evaluation of gastric emptying $(20,21)$.
The experimental day was preceded by a 1-week wash-out of blood glucose-lowering drugs. The participants were examined in a recumbent position in the morning after an overnight $(10 \mathrm{~h})$ fast that included medication, tobacco and liquids. An intravenous catheter was inserted into a cubital vein, and the catheterised arm was wrapped in a heating pad $\left(50^{\circ} \mathrm{C}\right)$ throughout the experiment for the collection of arterialised blood samples. Blood samples were drawn 15, 10 and 0 min before and 10, 20, 30, 40, 50, $60,75,90,120,150,180$ and $240 \mathrm{~min}$ after the ingestion of the test meal. The blood was transferred to dry tubes for coagulation (20 min at room temperature) for analyses of insulin and C-peptide. For analyses of GLP1, GIP and glucagon, blood was added to chilled tubes that contained EDTA and a specific DPP4 inhibitor (valine-pyrrolidide, final concentration $0.01 \mathrm{mmol} / \mathrm{l}$; a gift from Novo Nordisk, Bagsværd, Denmark). For analyses of paracetamol and DPP4

Table 2 Specific mutations. Ten patients with MODY2, ten patients with MODY3, and ten healthy individuals were included in the study. All of the mutations were heterozygous loss-of-function mutations, as confirmed by sequencing at the Steno Diabetes Center, Gentofte, Denmark. Three MODY2 patients were related: two siblings and their mother (GCK-6, GCK-7 and GCK-8).

\begin{tabular}{|c|c|c|c|}
\hline \multicolumn{2}{|c|}{ MODY2 } & \multicolumn{2}{|c|}{ MODY3 } \\
\hline Individual & $\begin{array}{l}\text { Mutation } \\
\text { (chromosome 7) }\end{array}$ & Individual & $\begin{array}{l}\text { Mutation } \\
\text { (chromosome 12) }\end{array}$ \\
\hline GCK-1 & Ivs $4+1 \mathrm{~g} \rightarrow \mathrm{a}$ & HNF1A-1 & Ivs4nt-2 \\
\hline GCK-2 & Thr255Ala & HNF1A-2 & Glu234Stop \\
\hline GCK-3 & Gln287Pro & HNF1A-3 & Pro291fsinsC \\
\hline GCK-4 & Leu292His & HNF1A-4 & Pro379fsdelCT \\
\hline GCK-5 & Cys220Trp & HNF1A-5 & Pro291fsinsC \\
\hline GCK-6 & Gly258Asp & HNF1A-6 & $\mathrm{C} 1623+1 \mathrm{~g} \rightarrow \mathrm{t}$ \\
\hline GCK-7 & Gly258Asp & HNF1A-7 & Ex2-10del \\
\hline GCK-8 & Gly258Asp & HNF1A-8 & Pro291fsinsC \\
\hline GCK-9 & Ile404fsdelAT & HNF1A-9 & Cys241Gly \\
\hline GCK-10 & Arg191Gln & HNF1A-10 & Gln124Stop \\
\hline
\end{tabular}


activity, blood was transferred into chilled tubes containing heparin. EDTA and heparin tubes were immediately cooled and kept on ice until centrifugation. All of the samples were centrifuged at $1200 \boldsymbol{g}$ for $20 \mathrm{~min}$ at $4{ }^{\circ} \mathrm{C}$. Serum samples for insulin and C-peptide analyses were stored at $-80^{\circ} \mathrm{C}$, and plasma samples for paracetamol, GLP1, GIP and glucagon analyses were stored at $-20^{\circ} \mathrm{C}$ until analysis. For bedside PG measurements, blood samples were transferred to sodium fluoride tubes and then immediately centrifuged at $7400 \boldsymbol{g}$ for $2 \mathrm{~min}$ at room temperature.

\section{Assays}

PG was measured by the glucose oxidase method using a glucose analyser (Yellow Springs Instrument Model 2300 STAT Plus analyser, YSI, Inc., Yellow Springs, OH, USA). Serum insulin and C-peptide concentrations were measured with a two-sided electro chemiluminescense immunoassay (Siemens Healthcare) (22). Plasma concentrations of total GIP and GLP1 were measured by RIAs as described previously $(23,24)$. We measured intact GLP1 with an ELISA, which is a two-sided sandwich assay that uses two monoclonal antibodies for catching the C-terminal end (GLP1F5) and the N-terminal end (Mab26.1) of the intact peptide (25). Intact GIP was measured using antibody code number 98171 as described previously (26). The glucagon assay is directed against the C-terminus of the glucagon molecule (antibody code number 4305) and measures primarily glucagon of pancreatic origin (27). For the GIP, GLP1 and glucagon assays, plasma samples (EDTA) were extracted with ethanol $(\sim 70 \%)$ before assaying to eliminate unspecific interference. Fasting DPP4 enzymatic activity was determined according to the method described by Nagakura et al. (28). Plasma paracetamol was measured by the Vitros ACET slide method (Ortho Clinical Diagnostics, Johnson \& Johnson Medical, Birkerød, Denmark) as described previously (20).

\section{Statistical analysis}

Baseline, peak and area under the curve (AUC) values are expressed as means \pm s.E.M. Differences resulting in $P$ values of $<0.05$ were considered significant. Linear mixed effect modelling was used for the analysis of longitudinal and repeated measures with statistical software R (R Foundation for Statistical Computing, Wirtschaftsuniversität, Vienna, Austria). Data were transformed according to distribution pattern, and family identity was used as a random variable (29).
A homogeneous or heterogeneous residual variance structure was chosen according to likelihood ratios. Bonferroni adjustments were used for post hoc analysis. AUCs were calculated using the trapezoidal rule and are presented as total AUCs unless otherwise stated. Insulin secretion rate (ISR) was calculated by deconvolution of measured C-peptide concentrations and the application of population-based parameters for C-peptide kinetics as described previously $(30,31)$. Insulin resistance was calculated according to the homoeostasis model assessment (HOMA-IR) (32). The number of participants was based on similar studies in other populations $(12,18,33,34,35,36)$.

\section{Results}

\section{Glucose}

Time courses for PG are illustrated in Fig. 1, and baseline, peak and AUC values are given in Table 3. Fasting PG (FPG) and peak PG were higher both in patients with MODY2 and in patients with MODY3 as compared to healthy CTRLs. Also, postprandial AUCs were greater in MODY patients, with patients with MODY3 exhibiting the most pronounced postprandial glucose intolerance.

\section{Insulin, C-peptide, ISR and insulin resistance}

Time courses for plasma insulin, C-peptide and ISR are illustrated in Fig. 2, and baseline, peak and AUC values are given in Table 3. Baseline values of insulin, C-peptide and ISR did not differ significantly across the groups. Patients with MODY3 exhibited lower postprandial responses of insulin and C-peptide as compared to patients with

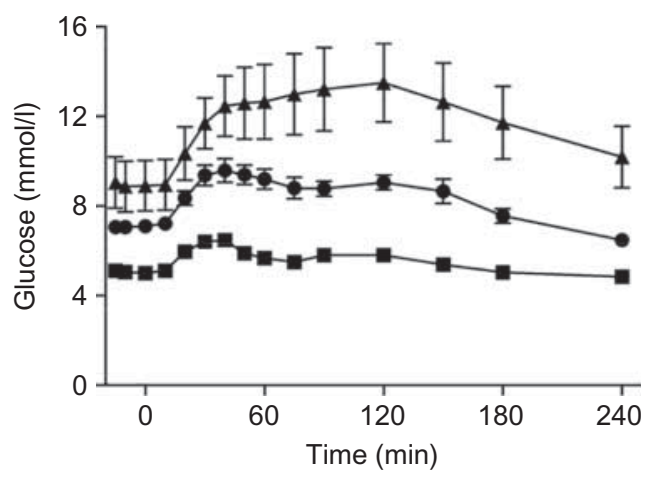

\section{Figure 1}

Plasma glucose (means \pm s.E.M.) following a standardised liquid test meal in healthy individuals (CTRLs) (squares) and in patients with MODY2 (circles) and MODY3 (triangles). 
Table 3 Glucose, insulin, C-peptide and ISR. All responses are calculated as total AUC (tAUC) and incremental AUC (iAUC).

\begin{tabular}{l}
\hline \\
\hline Glucose \\
Baseline $(\mathrm{mmol} / \mathrm{l})$ \\
Peak $(\mathrm{mmol} / \mathrm{l})$ \\
tAUC $(\mathrm{min} \times \mathrm{mmol} / \mathrm{l})$ \\
iAUC $(\min \times \mathrm{mmol} / \mathrm{l})$ \\
Insulin \\
Baseline $(\mathrm{pmol} / \mathrm{l})$ \\
Peak $(\mathrm{pmol} / \mathrm{l})$ \\
tAUC $(\mathrm{min} \times \mathrm{nmol} / \mathrm{l})$ \\
iAUC $(\mathrm{min} \times \mathrm{nmol} / \mathrm{l})$ \\
C-peptide \\
Baseline $(\mathrm{pmol} / \mathrm{l})$ \\
Peak $(\mathrm{pmol} / \mathrm{l})$ \\
tAUC $(\mathrm{min} \times \mathrm{nmol} / \mathrm{l})$ \\
iAUC $(\mathrm{min} \times \mathrm{nmol} / \mathrm{l})$ \\
ISR \\
Baseline $(\mathrm{pmol} / \mathrm{kg} \mathrm{per} \mathrm{min)}$ \\
Peak $(\mathrm{pmol} / \mathrm{kg} \mathrm{per} \min )$ \\
tAUC $(\mathrm{pmol} / \mathrm{kg})$ \\
iAUC $(\mathrm{pmol} / \mathrm{kg})$
\end{tabular}

\begin{tabular}{c}
\hline CTRL (1) $n=10$ \\
\hline \\
$5.1 \pm 0.1^{*(2,3)}$ \\
$6.7 \pm 0.2^{*(2,3)}$ \\
$1315 \pm 23^{*(2,3)}$ \\
$102 \pm 23^{*(3)}$ \\
$56 \pm 7$ \\
$472 \pm 48^{*(3)}$ \\
$49 \pm 7^{*(3)}$ \\
$35 \pm 6^{*(3)}$ \\
$413 \pm 45$ \\
$1526 \pm 124^{*(3)}$ \\
$241 \pm 26^{*(3)}$ \\
$142 \pm 5$ \\
$1 \pm 0$ \\
$8 \pm 1$ \\
$795 \pm 115^{*(2)}$ \\
$474 \pm 92^{*(2)}$
\end{tabular}

\begin{tabular}{c}
\hline MODY2 (2) $n=10$ \\
\hline $7.1 \pm 0.3^{*(1)}$ \\
$10.2 \pm 0.4^{*(1,3)}$ \\
$1984 \pm 51^{*(1,3)}$ \\
$287 \pm 49^{*(3)}$ \\
$70 \pm 17$ \\
$654 \pm 126^{*(3)}$ \\
$71 \pm 12^{*^{(3)}}$ \\
$57 \pm 9^{*(3)}$ \\
$470 \pm 80$ \\
$2038 \pm 239^{*(3)}$ \\
$320 \pm 40^{*(3)}$ \\
$208 \pm 25^{*(3)}$ \\
$2 \pm 0$ \\
$12 \pm 2^{*^{(3)}}$ \\
$828 \pm 120^{*(1,3)}$ \\
$525 \pm 84^{*(1,3)}$
\end{tabular}

\begin{tabular}{c}
\hline MODY3 $(3) n=10$ \\
\hline $8.9 \pm 0.8^{*(1)}$ \\
$14.4 \pm 1.7^{*(1,2)}$ \\
$2872 \pm 370^{*(1,2)}$ \\
$727 \pm 131^{*(1,2)}$ \\
$35 \pm 3$ \\
$245 \pm 30^{*(1,2)}$ \\
$26 \pm 3^{*(1,2)}$ \\
$17 \pm 3^{*(1,2)}$ \\
$329 \pm 12$ \\
$1052 \pm 89^{*(1,2)}$ \\
$177 \pm 12^{*(1,2)}$ \\
$98 \pm 12^{*(2)}$ \\
$1 \pm 0$ \\
$5 \pm 0{ }^{(2)}$ \\
$629 \pm 42^{*(2)}$ \\
$359 \pm 40^{*(2)}$
\end{tabular}

\begin{tabular}{c}
\hline $\boldsymbol{P}_{\text {ANOVA }}$ \\
\hline$<0.001$ \\
$<0.001$ \\
$<0.001$ \\
$<0.001$ \\
\\
0.058 \\
0.001 \\
0.001 \\
$<0.001$ \\
0.263 \\
0.002 \\
0.010 \\
0.004 \\
0.071 \\
0.003 \\
0.003 \\
0.002
\end{tabular}

Data are means \pm S.E.M. $P$ values are derived from one-way ANOVA for inter-load variations. Asterisk indicates significant differences $(P<0.05)$ from the group given in parentheses in the inter-load observations (post hoc analysis).

MODY2 and CTRLs. ISR values corresponded well to the C-peptide results, with lower values in patients with MODY3 as compared to patients with MODY2. The latter exhibited relatively high responses, but their responses did not differ from those of the CTRLs. HOMA-IR did not differ significantly between the three groups, although patients with MODY2 were numerically the most insulin-resistant (Table 1).

\section{Glucagon}

Time courses for plasma glucagon are illustrated in Fig. 3, and baseline values and baseline-subtracted AUCs are given in Table 4. Similar fasting values of glucagon were observed in the three groups, whereas pronounced postprandial hyperglucagonaemia was evident in patients with MODY3 as compared to patients with MODY2 and CTRLs (Fig. 3 and Table 4). No correlation between insulin and glucagon secretion was demonstrated (CTRLs: $r=0.057, \quad P=0.875 ;$ MODY2: $r=-0.238, \quad P=0.509$; MODY3: $r=-0.240, P=0.505$ ).

\section{GIP, GLP1 and DPP4 activity}

Time courses for plasma GIP and GLP1 are illustrated in Figs 4 and 5 respectively, and baseline, peak and AUC values are given in Table 4. Baseline and peak plasma GIP (total and intact) values were similar in all groups. Patients with MODY2 exhibited higher AUC for total GIP than that of patients with MODY3 (Fig. 4 and Table 4). A similar pattern was seen for intact GIP, although the differences in AUC did not reach statistical significance. Both total and intact baseline and peak plasma GLP1 values as well as postprandial AUC were similar in the three groups (Fig. 5 and Table 4). A significantly higher fasting DPP4 activity was found in patients with MODY3 as compared to CTRLs (Table 4). No correlations between the fasting DPP4 activity and intact GIP (iAUC: $r=0.082, P=0.823$; baseline values: $r=-0.054, P=0.881$ ) or intact GLP1 (iAUC: $r=-0.129, P=0.723$; baseline values: $r=-0.389$, $P=0.267)$ were observed.

\section{Gastric emptying (paracetamol)}

There were no significant differences in gastric emptying, as assessed by paracetamol excursions, between any of the groups according to time to peak plasma concentration $\left(T_{\max }\right)(C T R L s: 120 \pm 11 \mathrm{~min}$; MODY2: $122 \pm 15 \mathrm{~min}$; MODY3: $115 \pm 9 \min , P=0.782)$ or peak plasma concentration $\left(C_{\max }\right)$ (CTRLs: $0.100 \pm 0.007 \mathrm{mmol} / \mathrm{l}$; MODY2 $0.121 \pm 0.007 \mathrm{mmol} / \mathrm{l}$; MODY3: $0.108 \pm 0.007 \mathrm{mmol} / \mathrm{l}, P=0.115$ ).

\section{Discussion}

The primary findings in the present study were: i) inappropriately elevated postprandial glucagon levels in patients with MODY3; ii) normal postprandial responses 

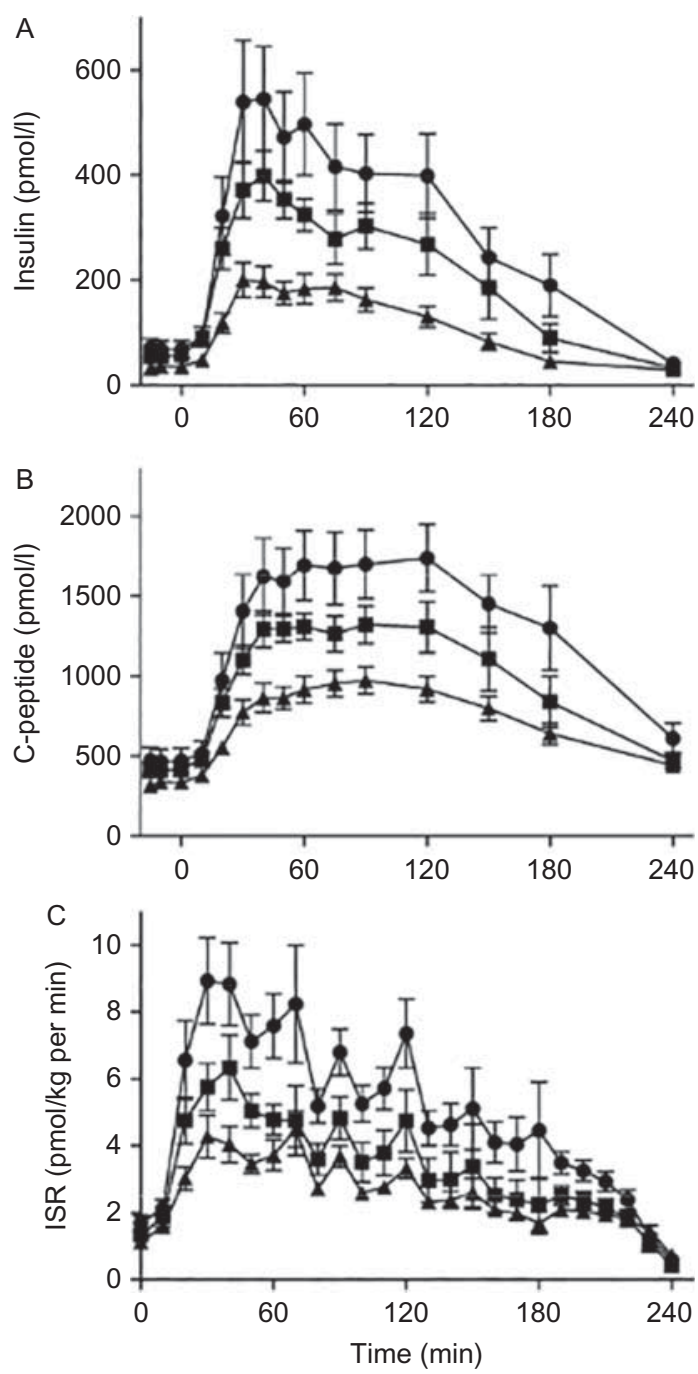

Figure 2

Plasma insulin (A), C-peptide (B) and insulin secretion rate (ISR) (C) (means \pm s.E.M.) following a standardised liquid test meal in healthy individuals (CTRLS) (squares) and in patients with MODY2 (circles) and MODY3 (triangles).

of the incretin hormones GLP1 (total and intact) and GIP (total) in patients with MODY2 and MODY3; and iii) exaggerated DPP4 enzymatic activity in patients with MODY3.

We performed the present study in two different types of MODY patients with defects in either GCK (MODY2) or HNF1A (MODY3) and in a control group of CTRLs. The included number of patients was limited but was based on similar studies performed previously in CTRLs and other patient groups $(12,18)$. We aimed to include non-related patients in order to reduce the effects of specific mutations, which resulted in both genetic and clinical heterogeneity. However, three related patients with MODY2 were included. To reduce confounding factors, only individuals without significant co-morbidity and without obesity were included in the present study.

Fasting and postprandial hyperglucagonaemia are common features of both type 1 diabetes (37) and type 2 diabetes $(9,19)$ as well as in other forms of diabetes (e.g. diabetes secondary to chronic pancreatitis (38)), and they contribute importantly to fasting and postprandial hyperglycaemia. The role of glucagon in the pathophysiology of the different forms of MODY has not been delineated. Only one study has previously examined postprandial glucagon levels in MODY patients, and it did so after meal ingestion with either a single dose of nateglinide, glibenclamide or placebo. In that study, patients with MODY3 exhibited impaired postprandial suppression of glucagon during both treatments and placebo (39). The inappropriate glucagon response found in patients with MODY3 in the present
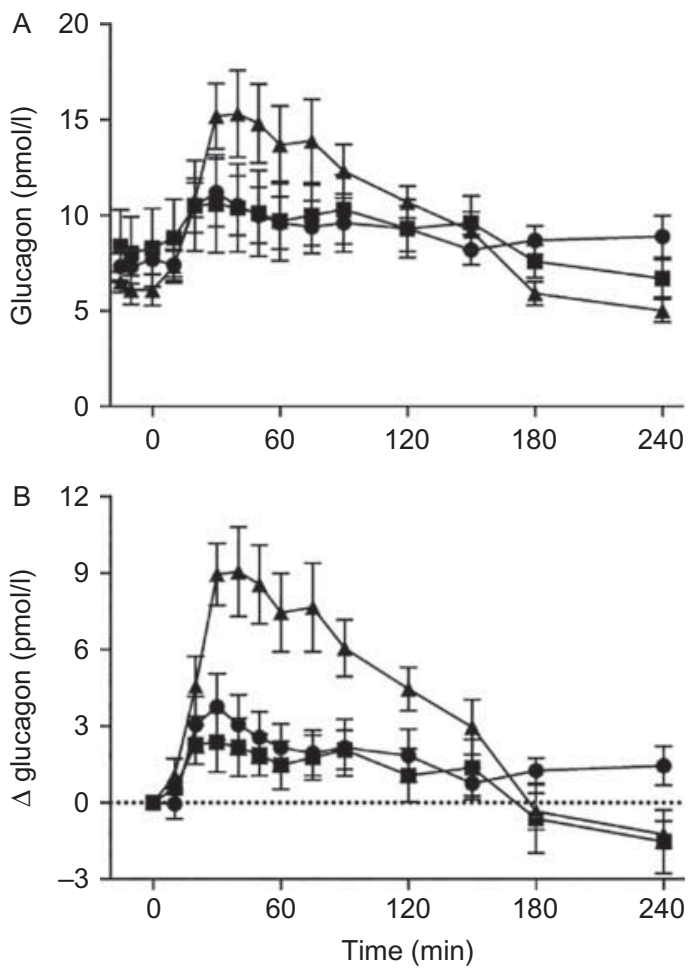

Figure 3

Plasma glucagon, absolute values (A) and baseline-subtracted values (B) (means \pm s.E.M.) following a standardised liquid test meal in healthy individuals (CTRLS) (squares) and in patients with MODY2 (circles) and MODY3 (triangles). 
Table 4 Glucagon, GIP, GLP1 and DPP4 activity. GIP and GLP1 (total and intact) responses represent tAUC and iAUC.

\begin{tabular}{|c|c|c|c|c|}
\hline & CTRL (1) $n=10$ & MODY2 (2) $n=10$ & MODY3 (3) $n=10$ & $\boldsymbol{P}_{\text {ANOVA }}$ \\
\hline \multicolumn{5}{|l|}{ Glucagon } \\
\hline Baseline (pmol/l) & $8 \pm 2$ & $7 \pm 1$ & $6 \pm 1$ & 0.787 \\
\hline tAUC $(\min \times \mathrm{pmol} / \mathrm{l})$ & $2158 \pm 338$ & $2194 \pm 260$ & $2334 \pm 196$ & 0.627 \\
\hline iAUC (min $\times$ pmol/l) & $182 \pm 176^{*(3)}$ & $410 \pm 154^{*(3, t)}$ & $838 \pm 108^{*(1,2, t)}$ & 0.017 \\
\hline \multicolumn{5}{|l|}{ GIP, total } \\
\hline Baseline (pmol/l) & $10 \pm 3$ & $9 \pm 2$ & $14 \pm 4$ & 0.169 \\
\hline Peak (pmol/l) & $109 \pm 9$ & $131 \pm 15$ & $104 \pm 9$ & 0.766 \\
\hline tAUC $(\min \times \mathrm{nmol} / \mathrm{l})$ & $13.9 \pm 1.3$ & $17.9 \pm 1.6$ & $12.7 \pm 0.7$ & 0.142 \\
\hline iAUC $(\min \times \mathrm{nmol} / \mathrm{l})$ & $11.4 \pm 1.7$ & $15.7 \pm 1.4^{*(3)}$ & $9.3 \pm 1.2 *(2)$ & 0.043 \\
\hline \multicolumn{5}{|l|}{ GIP, intact } \\
\hline Baseline $(\mathrm{pmol} / \mathrm{l})$ & $15 \pm 1$ & $14 \pm 1$ & $15 \pm 2$ & 0.838 \\
\hline Peak (pmol/l) & $81 \pm 7$ & $78 \pm 8$ & $75 \pm 7$ & 0.826 \\
\hline tAUC $(\min \times \mathrm{nmol} / \mathrm{l})$ & $10.4 \pm 0.7$ & $10.8 \pm 1.0$ & $9.0 \pm 0.5$ & 0.339 \\
\hline iAUC $(\min \times \mathrm{nmol} / \mathrm{l})$ & $6.9 \pm 0.6$ & $7.2 \pm 0.9$ & $5.3 \pm 0.5$ & 0.582 \\
\hline \multicolumn{5}{|l|}{ GLP1, total } \\
\hline Baseline (pmol/l) & $10 \pm 1$ & $8 \pm 1$ & $7 \pm 1$ & 0.118 \\
\hline Peak (pmol/l) & $27 \pm 2$ & $30 \pm 4$ & $30 \pm 5$ & 0.931 \\
\hline AUC $(\min \times \mathrm{nmol} / \mathrm{l})$ & $4.3 \pm 0.3$ & $4.1 \pm 0.4$ & $3.7 \pm 0.4$ & 0.410 \\
\hline iAUC $(\min \times \mathrm{nmol} / \mathrm{l})$ & $1.9 \pm 0.3$ & $2.2 \pm 0.4$ & $1.9 \pm 0.4$ & 0.744 \\
\hline \multicolumn{5}{|l|}{ GLP1, intact } \\
\hline Baseline $(\mathrm{pmol} / \mathrm{l})$ & $2 \pm 1$ & $1 \pm 0$ & $1 \pm 0$ & 0.275 \\
\hline Peak (pmol/l) & $7 \pm 2$ & $5 \pm 1$ & $7 \pm 1$ & 0.453 \\
\hline tAUC $(\min \times \mathrm{nmol} / \mathrm{l})$ & $1.0 \pm 0.2$ & $0.8 \pm 0.1$ & $1.0 \pm 0.1$ & 0.314 \\
\hline iAUC $(\min \times \mathrm{nmol} / \mathrm{l})$ & $0.5 \pm 0.1$ & $0.6 \pm 0.1$ & $0.7 \pm 0.1$ & 0.676 \\
\hline Fasting DPP4 activity (mU/ml) & $13.6 \pm 0.8^{*(3)}$ & $15.0 \pm 0.7$ & $17.7 \pm 1.2^{*(1)}$ & 0.012 \\
\hline
\end{tabular}

Data are means \pm s.E.M. $P$ values are derived from repeated measurement ANOVA for inter-load variations. Asterisk indicate significant differences $(P<0.05)$ from the group given in parentheses in the inter-load observations (post hoc analysis). ${ }^{\dagger}$ indicates $P=0.063$.

study correlates well with these findings. The cause of hyperglucagonaemia in patients with MODY3 could in theory be related specifically to the HNF1A defect. Notably, patients with MODY3 have an intracellular $\beta$ cell defect in the glucose metabolism, which results in the decreased production of ATP and thereby in diminished insulin release from $\beta$ cells (40). As in the $\beta$ cell, intracellular $\alpha$ cell ATP levels are important regulators of glucagon secretion (41). Additionally, HNF1A expression has been demonstrated in mouse $\alpha$ cells (42). Thus, if HNF1A is involved in $\alpha$ cell glucose metabolism, it seems possible that mutations in HNF1A might inhibit ATP production and thereby increase glucagon secretion. The reduced release of insulin from $\beta$ cells, perhaps in combination with a decreased effect of GIP and GLP1 on both $\alpha$ and $\beta$ cells, might also contribute to the inappropriate glucagon response. In agreement with this interpretation, patients with MODY2 who responded to the meals with increased insulin secretion showed normal suppression of glucagon.

The incretin hormones play a crucial role in lowering PG after the ingestion of nutrients. The insulinotropic effect of both GIP and GLP1 is glucose-dependent and strongly potentiated during high PG concentrations, whereas it wanes when glucose concentrations fall and ceases when PG levels are $<4-5 \mathrm{mmol} / \mathrm{l}$ (12). GLP1 inhibits upper gastrointestinal motility, which contributes to a flattening of postprandial PG excursions. Patients with type 2 diabetes are known to have reduced incretin effect. This is most likely the result of a markedly reduced insulinotropic effect of GIP and a reduced insulinotropic potency of GLP1 $(12,43)$. Studies of GIP secretion in patients with type 2 diabetes have shown both increased (44) and decreased secretion (19); hence, no clear association exists. A recent meta-analysis found preserved GIP secretion in patients with type 2 diabetes, although a reduced secretion may be associated with increasing age and $\mathrm{HbA1c}$, whereas high BMI seems to be associated with increased responses (45). Decreased levels of postprandial GLP1 secretion has been found in some studies of patients with type 2 diabetes $(18,19,46)$, whereas others have found preserved secretion $(27,47,48)$, and it seem to not be a universal characteristic for all type 2 diabetes patients (49). A meta-analysis that evaluated GLP1 secretion in patients with type 2 diabetes found an overall preserved secretion following OGTT and meals (50). However, 

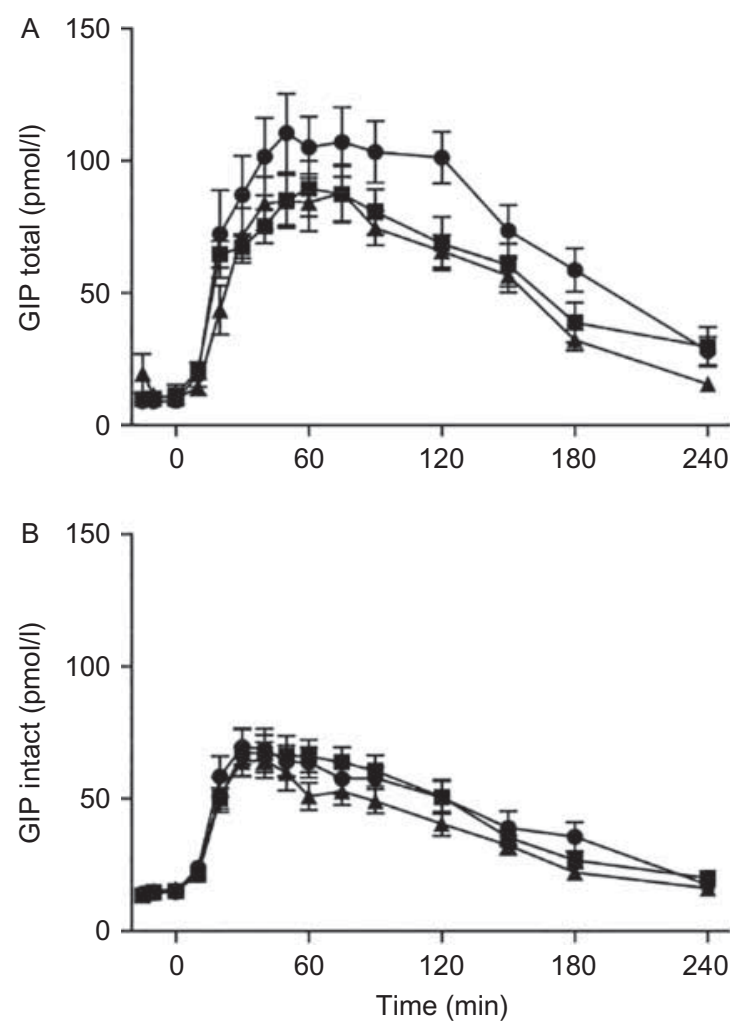

Figure 4

Plasma total glucose-dependent insulinotropic polypeptide (GIP) (A) and intact GIP (B) (means \pm s.E.M.) following a standardised liquid test meal in healthy individuals (CTRLs) (squares) and in patients with MODY2 (circles) and MODY3 (triangles).

decreased secretion of the incretin hormones, in particular GLP1, in patients with dysregulated type 2 diabetes and/or long-standing disease may contribute to the hyperglycaemia in these patients $(45,50)$. In one previous study, patients with MODY3 exhibited normal postprandial plasma GIP and GLP1 responses (16), which our group confirmed following OGTT (15). The present findings corroborate the idea that deficient incretin hormone responses do not seem to contribute to the phenotype of MODY3. In patients with MODY2, mixed meal-stimulated incretin hormone responses have not been examined. In one previous study, patients with MODY2 exhibited normal responses of both plasma GLP1 and GIP after a $2 \mathrm{~h} 75 \mathrm{~g}$ OGTT (17), which we confirmed following a $4 \mathrm{~h} 50 \mathrm{~g}$ OGTT (15). This is in line with our present findings of normal postprandial incretin hormone responses in MODY2, and it correlates well with the suggestion that patients with MODY2 have a $\beta$ cell-specific 'glucose-sensing' defect and with the suggestion that the expression of GCK in the mucosal L cell does not seem to affect circulating incretin hormone levels $(4,17)$.

As mentioned earlier, the gene defect in MODY3 might compromise the activity of DPP4 in enterocytes and the liver and in turn increase circulating levels of intact incretin hormones (14). However, no indications of elevated intact GLP1 or intact GIP levels in MODY3 were observed. In contrast, exaggerated DPP4 activity was demonstrated in patients with MODY3 as compared to CTRLs, but this was not reflected in the plasma levels of the intact hormones. Thus, the gene defect in MODY3 does not seem to affect the plasma concentrations of intact incretin hormones in the peripheral circulation. Nevertheless, further studies of this potential 'endogenous DPP4 inhibition' in MODY3 could identify local effects in the intestinal mucosa or in the portal vein and the liver.

The two types of MODY patients are very unique and are difficult to recruit because of the low prevalence of MODY2 and MODY3. The limited number of patients in the present study may have induced a risk of type II error
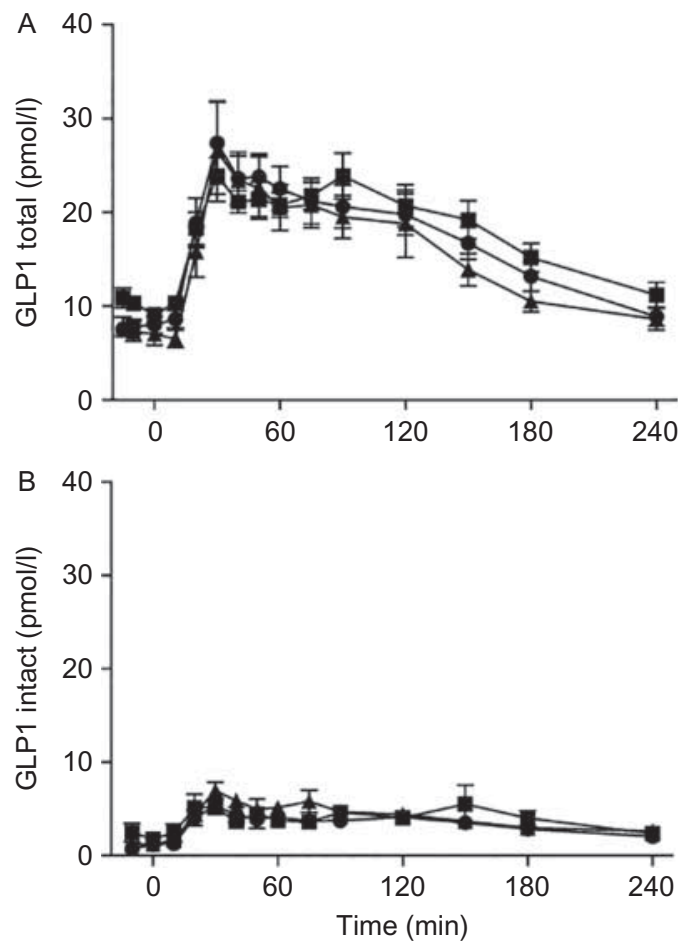

\section{Figure 5}

Plasma total glucagon-like peptide 1 (GLP1) (A) and intact GLP1 (B) (means \pm s.E.M.) following a standardised liquid test meal in healthy individuals (CTRLs) (squares) and in patients with MODY2 (circles) and MODY3 (triangles). 
and should be considered when drawing conclusions about the results.

In conclusion, both patients with MODY2 and patients with HNF1 diabetes have normal postprandial plasma responses of GIP and GLP1, and patients with MODY3 exhibit increased plasma DPP4 activity as well as marked postprandial hyperglucagonaemia. Hyperglucagonaemia and increased DPP4 activity in MODY3 may represent relevant therapeutic targets (51) for drugs with glucagon-lowering and/or DPP4-inhibiting properties. Interestingly, very recent data from our group demonstrated a glucose-lowering effect on both FPG and postprandial PG during treatment with a GLP1 receptor agonist, but no significant effect on postprandial glucagon responses was demonstrated (51).

\section{Declaration of interest}

The authors declare that there is no conflict of interest that could be perceived as prejudicing the impartiality of the research reported.

\section{Funding}

This work was supported by unrestricted grants from the Danish Order of Freemasons - Grand Lodge of Denmark and from the Novo Nordisk Foundation (NNF). The NNF Center for Basic Metabolic Research is an independent Research Center at the University of Copenhagen, Denmark, and is partially funded by an unrestricted donation from the Novo Nordisk Foundation (http://metabol.ku.dk/). Clinical Trial Registration number: NCT01342939.

\section{Author contribution statement}

S $\mathrm{H}$ Østoft contributed to the study design, performed the study, researched the data and wrote the manuscript. J I Bagger contributed to the statistical analyses and reviewed and edited the manuscript. T Hansen contributed to the study design, contributed together with $O$ Pedersen to the recruitment of MODY patients and reviewed and edited the manuscript. J J Holst and B Hartmann analysed the plasma for incretin hormones, glucagon and DPP4 activity and reviewed and edited the manuscript. F K Knop contributed to the study design and reviewed and edited the manuscript. T Vilsbøll designed the study and reviewed and edited the manuscript. S H Østoft is the guarantor of this work and, as such, had full access to all of the data in the study and takes responsibility for the integrity of the data and the accuracy of the data analysis. Preliminary results have been presented as posters at the 72nd Scientific Sessions of the American Diabetes Association (ADA), Philadelphia, PA, USA (2012), the 73rd Scientific Sessions of the ADA, Chicago, IL, USA (2013) and the 49th Annual Meeting of the EASD, Barcelona, Spain (2013).

\section{Acknowledgements}

We thank all of the participants for spending time on this project, and we are grateful for the expert technical assistance provided by J Purtoft and N Kjeldsen, Center for Diabetes Research, Gentofte Hospital, University of Copenhagen, Denmark, and by L Albæk and S Pilgaard, Department of Biomedical Sciences, University of Copenhagen, Denmark.

\section{References}

1 Hattersley A, Bruining J, Shield J, Njolstad P \& Donaghue K. International Society for Pediatric and Adolescent Diabetes. ISPAD Clinical Practice Consensus Guidelines 2006-2007. The diagnosis and management of monogenic diabetes in children. Pediatric Diabetes 2006 7 352-360. (doi:10.1111/j.1399-5448.2006.00217.x)

2 Andersen G, Hansen T \& Pedersen O. Genetics of common forms of glycaemia with pathological impact on vascular biology: are we on the right track? Current Molecular Medicine 20055 261-274. (doi:10.2174/ 1566524053766077)

3 Johansen A, Ek J, Mortensen HB, Pedersen O \& Hansen T. Half of clinically defined maturity-onset diabetes of the young patients in Denmark do not have mutations in HNF4A, GCK, and TCF1. Journal of Clinical Endocrinology and Metabolism 200590 4607-4614. (doi:10.1210/ jc.2005-0196)

4 Murphy R, Ellard S \& Hattersley AT. Clinical implications of a molecular genetic classification of monogenic $\beta$-cell diabetes. Nature Clinical Practice. Endocrinology \& Metabolism 20084 200-213. (doi:10.1038/ ncpendmet0778)

5 Shepherd M, Ellis I, Ahmad AM, Todd PJ, Bowen-Jones D, Mannion G, Ellard S, Sparkes AC \& Hattersley AT. Predictive genetic testing in maturity-onset diabetes of the young (MODY). Diabetic Medicine 2001 18 417-421. (doi:10.1046/j.1464-5491.2001.00447.x)

6 Pearson ER, Starkey BJ, Powell RJ, Gribble FM, Clark PM \& Hattersley AT. Genetic cause of hyperglycaemia and response to treatment in diabetes. Lancet 2003362 1275-1281. (doi:10.1016/ S0140-6736(03)14571-0)

7 Møller AM, Dalgaard LT, Pociot F, Nerup J, Hansen T \& Pedersen O. Mutations in the hepatocyte nuclear factor- $1 \alpha$ gene in Caucasian families originally classified as having type I diabetes. Diabetologia 1998 41 1528-1531. (doi:10.1007/s001250051101)

8 Stride A, Vaxillaire M, Tuomi T, Barbetti F, Njølstad PR, Hansen T, Costa A, Conget I, Pedersen O, Søvik O et al. The genetic abnormality in the $\beta$ cell determines the response to an oral glucose load. Diabetologia 200245 427-435. (doi:10.1007/s00125-001-0770-9)

9 Knop FK, Vilsbøll T, Madsbad S, Holst JJ \& Krarup T. Inappropriate suppression of glucagon during OGTT but not during isoglycaemic i.v. glucose infusion contributes to the reduced incretin effect in type 2 diabetes mellitus. Diabetologia 200750 797-805. (doi:10.1007/s00125006-0566-z)

10 Shah P, Vella A, Basu A, Basu R, Schwenk WF \& Rizza RA. Lack of suppression of glucagon contributes to postprandial hyperglycemia in subjects with type 2 diabetes mellitus. Journal of Clinical Endocrinology and Metabolism 200085 4053-4059. (doi:10.1210/jcem.85.11.6993)

11 Holst JJ. On the physiology of GIP and GLP-1. Hormone and Metabolic Research 200436 747-754. (doi:10.1055/s-2004-826158)

12 Vilsbøll T, Krarup T, Madsbad S \& Holst JJ. Both GLP-1 and GIP are insulinotropic at basal and postprandial glucose levels and contribute nearly equally to the incretin effect of a meal in healthy subjects. Regulatory Peptides 2003114 115-121. (doi:10.1016/S0167-0115(03) 00111-3)

13 Hare KJ, Vilsbøll T, Asmar M, Deacon CF, Knop FK \& Holst JJ. The glucagonostatic and insulinotropic effects of glucagon-like peptide 1 contribute equally to its glucose-lowering action. Diabetes 201059 1765-1770. (doi:10.2337/db09-1414)

14 Erickson RH, Gum JR, Lotterman CD, Hicks JW, Lai RS \& Kim YS. Regulation of the gene for human dipeptidyl peptidase IV by hepatocyte nuclear factor $1 \alpha$. Biochemical Journal 1999338 (Pt 1) 91-97. (doi:10.1042/0264-6021:3380091)

15 Østoft SH, Bagger JI, Hansen T, Pedersen O, Holst JJ, Knop FK \& Vilsbøll T. Incretin effect and glucagon responses to oral and intravenous glucose in patients with maturity-onset diabetes of the young-type 2 and type 3. Diabetes 201463 2838-2844. (doi:10.2337/ db13-1878) 
16 Ekholm E, Shaat $\mathrm{N} \&$ Holst JJ. Characterization of $\beta$ cell and incretin function in patients with MODY1 (HNF4A MODY) and MODY3 (HNF1A MODY) in a Swedish patient collection. Acta Diabetologica 2012 49 349-354. (doi:10.1007/s00592-011-0312-y)

17 Murphy R, Tura A, Clark PM, Holst JJ, Mari A \& Hattersley AT. Glucokinase, the pancreatic glucose sensor, is not the gut glucose sensor. Diabetologia 200952 154-159. (doi:10.1007/s00125-008-1183-9)

18 Vilsbøll T, Krarup T, Deacon CF, Madsbad S \& Holst JJ. Reduced postprandial concentrations of intact biologically active glucagon-like peptide 1 in type 2 diabetic patients. Diabetes 200150 609-613. (doi:10.2337/diabetes.50.3.609)

19 Toft-Nielsen MB, Damholt MB, Madsbad S, Hilsted LM, Hughes TE, Michelsen BK \& Holst JJ. Determinants of the impaired secretion of glucagon-like peptide-1 in type 2 diabetic patients. Journal of Clinical Endocrinology and Metabolism 200186 3717-3723. (doi:10.1210/jcem. 86.8.7750)

20 Miceli JN, Aravind MK, Cohen SN \& Done AK. Simultaneous measurements of acetaminophen and salicylate in plasma by liquid chromatography. Clinical Chemistry 197925 1002-1004.

21 Medhus AW, Lofthus CM, Bredesen J \& Husebye E. Gastric emptying: the validity of the paracetamol absorption test adjusted for individual pharmacokinetics. Neurogastroenterology and Motility 200113179. (doi:10.1046/j.1365-2982.2001.00249.x)

22 Bablok W, Passing H, Bender R \& Schneider B. A general regression procedure for method transformation. Application of linear regression procedures for method comparison studies in clinical chemistry, Part III. Journal of Clinical Chemistry and Clinical Biochemistry 198826 783-790.

23 Krarup T \& Holst JJ. The heterogeneity of gastric inhibitory polypeptide in porcine and human gastrointestinal mucosa evaluated with five different antisera. Regulatory Peptides 19849 35-46. (doi:10.1016/01670115(84)90005-3)

24 Ørskov C, Rabenhøj L, Wettergren A, Kofod H \& Holst JJ. Tissue and plasma concentrations of amidated and glycine-extended glucagonlike peptide I in humans. Diabetes 199443 535-539. (doi:10.2337/diab. 43.4.535)

25 Vilsbøll T, Krarup T, Sonne J, Madsbad S, Vølund A, Juul AG \& Holst JJ. Incretin secretion in relation to meal size and body weight in healthy subjects and people with type 1 and type 2 diabetes mellitus. Journal of Clinical Endocrinology and Metabolism 200388 2706-2713. (doi:10.1210/ jc.2002-021873)

26 Deacon CF, Nauck MA, Meier J, Hücking K \& Holst JJ. Degradation of endogenous and exogenous gastric inhibitory polypeptide in healthy and in type 2 diabetic subjects as revealed using a new assay for the intact peptide. Journal of Clinical Endocrinology and Metabolism 200085 3575-3581. (doi:10.1210/jcem.85.10.6855)

27 Ørskov C, Jeppesen J, Madsbad S \& Holst JJ. Proglucagon products in plasma of noninsulin-dependent diabetics and nondiabetic controls in the fasting state and after oral glucose and intravenous arginine. Journal of Clinical Investigation 199187 415-423. (doi:10.1172/ JCI115012)

28 Nagakura T, Yasuda N, Yamazaki K, Ikuta H \& Tanaka I. Enteroinsular axis of $\mathrm{db} / \mathrm{db}$ mice and efficacy of dipeptidyl peptidase IV inhibition. Metabolism: Clinical and Experimental 200352 81-86. (doi:10.1053/ meta.2003.50014)

29 Verbeke G \& Molenberghs G. A model for longitudidal data. In Linear Mixed Models for Longitudinal Data, ch 3, pp 23-26, 2000.

30 Kjems LL, Christiansen E, Vølund A, Bergman RN \& Madsbad S. Validation of methods for measurement of insulin secretion in humans in vivo. Diabetes 200049 580-588. (doi:10.2337/diabetes.49. 4.580)

31 Kjems LL, Vølund A \& Madsbad S. Quantification of $\beta$-cell function during IVGTT in type II and non-diabetic subjects: assessment of insulin secretion by mathematical methods. Diabetologia $2001 \mathbf{4 4}$ 1339-1348. (doi:10.1007/s001250100639)
32 Turner RC, Holman RR, Matthews D, Hockaday TD \& Peto J. Insulin deficiency and insulin resistance interaction in diabetes: estimation of their relative contribution by feedback analysis from basal plasma insulin and glucose concentrations. Metabolism: Clinical and Experimental 197928 1086-1096. (doi:10.1016/0026-0495(79) 90146-X)

33 Højberg PV, Vilsbøll T, Zander M, Knop FK, Krarup T, Vølund A, Holst JJ $\&$ Madsbad S. Four weeks of near-normalization of blood glucose has no effect on postprandial GLP-1 and GIP secretion, but augments pancreatic B-cell responsiveness to a meal in patients with Type 2 diabetes. Diabetic Medicine 200825 1268-1275. (doi:10.1111/ j.1464-5491.2008.02579.x)

34 Hansen KB, Vilsbøll T, Bagger JI, Holst JJ \& Knop FK. Increased postprandial GIP and glucagon responses, but unaltered GLP-1 response after intervention with steroid hormone, relative physical inactivity, and high-calorie diet in healthy subjects. Journal of Clinical Endocrinology and Metabolism 201196 447-453. (doi:10.1210/ jc.2010-1605)

35 Bonde L, Vilsbøll T, Nielsen T, Bagger JI, Svare JA, Holst JJ, Larsen S \& Knop FK. Reduced postprandial GLP-1 responses in women with gestational diabetes mellitus. Diabetes, Obesity \& Metabolism 201315 713-720. (doi:10.1111/dom.12082)

36 Idorn T, Knop FK, Jørgensen M, Holst JJ, Hornum M \& FeldtRasmussen B. Postprandial responses of incretin and pancreatic hormones in non-diabetic patients with end-stage renal disease. Nephrology, Dialysis, Transplantation 201429 119-127. (doi:10.1093/ ndt/gft353)

37 Hare KJ, Vilsbøll T, Holst JJ \& Knop FK. Inappropriate glucagon response after oral compared with isoglycemic intravenous glucose administration in patients with type 1 diabetes. American Journal of Physiology-Endocrinology and Metabolism 2010298 E832-E837. (doi:10.1152/ajpendo.00700.2009)

38 Knop FK, Vilsbøll T, Højberg PV, Larsen S, Madsbad S, Vølund A, Holst JJ \& Krarup T. Reduced incretin effect in type 2 diabetes: cause or consequence of the diabetic state? Diabetes 200756 1951-1959. (doi:10.2337/db07-0100)

39 Tuomi T, Honkanen EH, Isomaa B, Sarelin L \& Groop LC. Improved prandial glucose control with lower risk of hypoglycemia with nateglinide than with glibenclamide in patients with maturity-onset diabetes of the young type 3. Diabetes Care 200629 189-194. (doi:10.2337/diacare.29.02.06.dc05-1314)

40 Pontoglio M, Sreenan S, Roe M, Pugh W, Ostrega D, Doyen A, Pick AJ, Baldwin A, Velho G, Froguel P et al. Defective insulin secretion in hepatocyte nuclear factor $1 \alpha$-deficient mice. Journal of Clinical Investigation 1998101 2215-2222. (doi:10.1172/JCI2548)

41 Gromada J, Franklin I \& Wollheim CB. $\alpha$-Cells of the endocrine pancreas: 35 years of research but the enigma remains. Endocrine Reviews 200728 84-116. (doi:10.1210/er.2006-0007)

42 Nammo T, Yamagata K, Tanaka T, Kodama T, Sladek FM, Fukui K, Katsube F, Sato Y, Miyagawa J-I \& Shimomura I. Expression of HNF-4 $\alpha$ (MODY1), HNF-1 $\beta$ (MODY5), and HNF-1 $\alpha$ (MODY3) proteins in the developing mouse pancreas. Gene Expression Patterns 20088 96-106. (doi:10.1016/j.modgep.2007.09.006)

43 Vilsbøll T, Holst JJ \& Knop FK. The spectrum of antidiabetic actions of GLP-1 in patients with diabetes. Best Practice \& Research. Clinical Endocrinology \& Metabolism 200923 453-462. (doi:10.1016/j.beem. 2009.03.011)

44 Jones IR, Owens DR, Luzio S, Williams S \& Hayes TM. The glucose dependent insulinotropic polypeptide response to oral glucose and mixed meals is increased in patients with type 2 (non-insulindependent) diabetes mellitus. Diabetologia 198932 668-677. (doi:10.1007/BF00274255)

45 Calanna S, Christensen M, Holst JJ, Laferrère B, Gluud LL, Vilsbøll T \& Knop FK. Secretion of glucose-dependent insulinotropic polypeptide in patients with type 2 diabetes: systematic review and meta-analysis 
of clinical studies. Diabetes Care 201336 3346-3352. (doi:10.2337/ dc13-0465)

46 Muscelli E, Mari A, Casolaro A, Camastra S, Seghieri G, Gastaldelli A, Holst JJ \& Ferrannini E. Separate impact of obesity and glucose tolerance on the incretin effect in normal subjects and type 2 diabetic patients. Diabetes 200857 1340-1348. (doi:10.2337/ db07-1315)

47 Ryskjaer J, Deacon CF, Carr RD, Krarup T, Madsbad S, Holst J \& Vilsbøll T. Plasma dipeptidyl peptidase-IV activity in patients with type-2 diabetes mellitus correlates positively with HbA1c levels, but is not acutely affected by food intake. European Journal of Endocrinology/European Federation of Endocrine Societies 2006155 485-493. (doi:10.1530/eje.1.02221)

48 Vollmer K, Holst JJ, Baller B, Ellrichmann M, Nauck MA, Schmidt WE \& Meier JJ. Predictors of incretin concentrations in subjects with normal, impaired, and diabetic glucose tolerance. Diabetes 200857 678-687. (doi:10.2337/db07-1124)

49 Nauck MA, Vardarli I, Deacon CF, Holst JJ \& Meier JJ. Secretion of glucagon-like peptide-1 (GLP-1) in type 2 diabetes: what is up, what is down? Diabetologia 201154 10-18. (doi:10.1007/ s00125-010-1896-4)

50 Calanna S, Christensen M, Holst JJ, Laferrère B, Gluud LL, Vilsbøll T \& Knop FK. Secretion of glucagon-like peptide-1 in patients with type 2 diabetes mellitus: systematic review and meta-analyses of clinical studies. Diabetologia 201356 965-972. (doi:10.1007/s00125-013-2841-0)

51 Østoft SH, Bagger JI, Hansen T, Pedersen O, Faber J, Holst JJ, Knop FK \& Vilsbøll T. Glucose-lowering effects and low risk of hypoglycemia in patients with maturity-onset diabetes of the young when treated with a GLP-1 receptor agonist: a double-blind, randomized, crossover trial. Diabetes Care 201437 1797-1805. (doi:10.2337/dc13-3007)

Received 19 January 2015

Revised version received 9 April 2015

Accepted 7 May 2015 